\title{
O lugar dos ensaios clínicos aleatorizados na pesquisa em psicoterapia: uma crítica epistemológica
}

\author{
Thiago Pacheco de Almeida Sampaio ${ }^{a *}$ \\ Francisco Lotufo Neto ${ }^{\text {b }}$ (D) \\ aUniversidade de São Paulo, Instituto de Psicologia. São Paulo, SP, Brasil

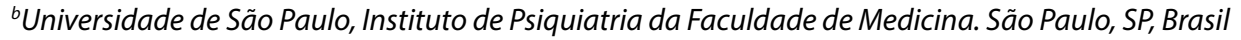

\begin{abstract}
Resumo: O Ensaio Clínico Aleatorizado (ECA) é considerado o tipo de desenho metodológico com maior poder de verificação da eficácia das psicoterapias. Entretanto, especialmente a partir da segunda metade do século $\mathrm{XX}$, muitas críticas direcionadas às concepções epistemológicas subjacentes às ditas "ciências duras" atingiram também, no âmbito das ciências da saúde, os estudos que adotavam esse desenho. Este artigo é uma reflexão crítica sobre algumas das objeções feitas aos ECAs, avaliando de que maneira e até que ponto estes poderiam se configurar como estratégia válida de investigação científica no contexto crítico apontado. Conclui-se que o ECA pode e deve ser utilizado - desde que em contexto crítico - por seu valor pragmático, enquanto produtor de predições e intervenções capazes de solucionar problemas clínicos, inevitavelmente definidos e estabelecidos a partir do ponto de vista particular de uma comunidade.
\end{abstract}

Palavras-chave: ensaio clínico randomizado, práticas baseadas em evidências, epistemologia, pragmatismo, behaviorismo.

A disseminação dos Ensaios Clínicos Aleatorizados (ECA) está diretamente associada à emergência do movimento político-científico denominado Medicina Baseada em Evidências (MBE) (Cook, Shwartz, \& Kaslow, 2017). Esse movimento começa a se desenvolver nos anos 1970 a partir do trabalho de epidemiologistas clínicos nas universidades de McMaster e Oxford, propondo um novo paradigma para a pesquisa e a prática da clínica médica (Solomon, 2011). Organizados a partir de $1992 \mathrm{em}$ um grupo de trabalho (Evidence-Based Medicine Working Group), esses pesquisadores tinham como objetivo propor critérios que fossem capazes de avaliar e julgar a qualidade da produção científica sobre tratamentos médicos, gerando um ranking que estabeleceria o que chamaram de "melhor evidência disponível". Assumia-se, assim, que tal empreendimento teria impactos sociais importantes, informando médicos, pacientes e agentes de políticas públicas sobre os melhores tratamentos para cada condição clínica, tornando-os, deste modo, menos susceptíveis a terapias pseudocientíficas e tratamentos inócuos ou perniciosos.

De acordo com Solomon (2011), atualmente, a despeito de haver discordância entre diferentes grupos que discutem essa questão, o ECA aparece, geralmente, como o desenho de pesquisa produtor do maior grau de evidência em estudos sobre a eficácia e a efetividade de intervenções clínicas (superado apenas pelas revisões sistemáticas e metanálises de ECAs). Os ensaios clínicos sem cegamento

*Endereço para correspondência: sampaiothiago@hotmail.com e abertos estariam um degrau abaixo, seguidos pelos estudos de caso-controle, estudos de coorte, estudos observacionais e, por fim, pelos estudos de caso. Alguns protocolos consideram, ainda, as pesquisas laboratoriais e estudos com animais, além da "opinião consensual de especialistas" e da "experiência clínica" (Hujoel, 2009) quando não há evidências melhores disponíveis.

O ECA é um método nomotético de investigação usado para verificar a eficácia de uma intervenção terapêutica para um quadro clínico determinado por meio da comparação entre grupos; o que requer uniformidade e precisão diagnósticas, além de garantia de que todos os participantes preencham os mesmos critérios de inclusão estabelecidos para o estudo (Haaga \& Stiles, 2000). A partir disso, é possível controlar estatisticamente a influência de fatores inespecíficos nos resultados, utilizando um número suficientemente grande de participantes e alocando-os aleatoriamente às condições de tratamento que serão comparadas (Hollom, 2006; Kendall, 2003). Os ECA são particularmente úteis para comparar intervenções farmacológicas que permitem padronizar com bastante precisão o tratamento recebido em cada grupo.

No âmbito específico da psicopatologia, de acordo com Shorter (2015), o avanço da psicofarmacologia, a partir dos anos 1960, impulsionou a psiquiatria norte-americana ao reascender a hipótese de uma etiologia biológica discreta e específica dos transtornos mentais, levando à consequente rejeição das categorias psicanalíticas que nortearam as duas primeiras edições do 
Manual Diagnóstico e Estatístico dos Transtornos Mentais (DSM I e II) da American Psychological Association (APA). Esse fato histórico aproximou a psiquiatria de outras disciplinas médicas que se dedicavam ao tratamento de doenças com causas orgânicas identificáveis, tanto pela compreensão da natureza de seus objetos quanto pelo método de investigação adotado: o ECA. A resposta clínica a psicotrópicos específicos também passou a ser usada como parâmetro na investigação etiológica (Ioannidis, 2015), porém, como os mecanismos de ação de drogas que tinham efeitos clínicos positivos em pacientes psiquiátricos não eram totalmente conhecidos, uma proposta nosológica sindrômica, baseada em agrupamento de sintomas (i.e. DSM-III), foi proposta como um passo intermediário à investigação do substrato biológico dos transtornos mentais.

Nesse contexto surgem algumas propostas psicoterapêuticas mais diretivas e tecnicamente orientadas ao tratamento de transtornos definidos a partir das novas tendências nosológicas da psiquiatria. Protocolos terapêuticos estruturados, geralmente de base teórica comportamental e/ou cognitiva (Beck, 1964; Wolpe, 1968), podiam ser aplicados por meio de manuais, o que favorecia a padronização e checagem da qualidade e fidedignidade da intervenção, garantindo a validade interna e a replicabilidade de ECAs (Lambert \& Ogles, 2004). Isso tornou possível, inclusive, a comparação direta de intervenções farmacológicas e psicoterapêuticas (Klein, 1997). Agrupados sob o nome Terapia Cognitivo-Comportamental (TCC), esses protocolos psicoterapêuticos elevaram o status científico da psicoterapia, e não tardou que ECAs atestassem sua eficácia no tratamento de diferentes quadros psiquiátricos (Butler, Chapman, Forman, \& Beck, 2006).

\section{Práticas Baseadas em Evidências em Psicologia (PBEP)}

Adotando uma perspectiva similar à da MBE, em 2006, a força-tarefa sobre Práticas Baseadas em Evidência em Psicologia (PBEP) da APA publicou um artigo com o objetivo de estabelecer critérios valorativos em relação ao grau de evidência proporcionado por cada tipo específico de pesquisa e desenho experimental utilizado e, a partir disso, elaborar (1) uma hierarquia que permitisse estabelecer a melhor evidência disponível; e (2) um ranking das terapias que reúnem mais evidências de eficácia, efetividade, entre outros desfechos de relevância clínica, para populações com quadros específicos (American Psychological Association, 2006). A forçatarefa reuniu "cientistas e praticantes de uma ampla gama de perspectivas e tradições, refletindo as diversas perspectivas dentro do campo [da psicologia]" (p. 273). O relatório é resultado desse esforço coletivo, e a análise de alguns trechos conclusivos nos ajudará na introdução à questão que será aqui apresentada.
O documento visa estabelecer, no âmbito clínico, diretrizes para as PBEP e, após salientar a importância de reconhecer o valor de múltiplas fontes de evidência científica no estudo da psicoterapia, os autores concluem que:

Em uma dada circunstância clínica, psicólogos de boa fé e bom julgamento podem discordar sobre o melhor jeito de pesar diferentes formas de evidência; com o passar do tempo, a ampla investigação empírica - no laboratório e na clínica - apontará o caminho para as melhores práticas através da integração da melhor evidência. $\mathrm{O}$ que este documento reflete, no entanto, é a reafirmação do que psicólogos sabem há um século: o método científico é uma maneira de pensar e observar sistematicamente, e é a melhor ferramenta que temos para aprender sobre o que funciona para quem. (American Psychological Association, 2006, p. 280, grifo nosso)

Os autores encerram o artigo afirmando que "nosso objetivo neste documento e nas deliberações da força tarefa foi estabelecer uma agenda e um tom para os próximos passos na evolução das práticas psicológicas baseadas em evidência" (American Psychological Association, 2006, p. 281, grifo nosso).

O termo "método científico" dá margem a diferentes interpretações da afirmação feita na primeira citação, a depender de como é compreendido. No caso de uma interpretação representacionista (Rorty, 1979) o (único) "método científico" seria entendido como o (único) meio adequado para testar hipóteses e produzir conhecimento verdadeiro, sua base epistemológica seria universal e estaria, por definição, imune a determinantes subjetivos ou contextuais. Seus procedimentos seriam capazes de controlar os potenciais vieses causados por esses fatores, tornando os resultados das pesquisas mais próximos de uma representação fidedigna do real. Mesmo assumindo que a capacidade de apreensão empírica e compreensão racional sejam limitadas, seja pela influência das paixões da alma (Descartes, 1684/2007) ou por categorias a priori do intelecto (Kant, 1781/1983), o controle dessas variáveis pela adequada utilização do método científico garantiria o conhecimento mais próximo possível de uma realidade independente da subjetividade do observador (i.e. realidade objetiva). Esta característica também poderia ser identificada na segunda citação, caso o estabelecimento da "agenda e do tom" se pretenda isenta ou baseada em parâmetros objetivos, atemporais e, por isso, supostamente científicos.

Se for esse o caso, a proposta parte da perspectiva positivista, caracterizada pelo realismo científico representacionista, pela negação da metafísica e pelo posicionamento oposto à perspectiva ontológica contextualista (Pepper, 1942/1970) enquanto possível base de sustentação epistemológica da ciência (Rorty, 1979). Entretanto é possível que a extração dessas citações de seu contexto amplo e da estrutura lógico-argumentativa 
do texto possa nos levar a uma espécie de precipitação interpretativa. Isso ocorreria ao concluirmos, equivocadamente, que por trás dessas afirmações esteja, necessariamente, a assunção dos elementos essenciais da proposta positivista, especialmente em relação à compreensão da natureza e do papel das evidências na pesquisa científica e, consequentemente, das propostas metodológicas que viessem a se estabelecer como prioritárias na sua produção (i.e. os ECAs).

Embora a análise crítica mais detalhada do documento extrapole o escopo deste artigo, há duas características que devem ser consideradas como exemplo de manifestação do fenômeno-alvo das críticas pós-modernas ao positivismo. Primeiramente, mesmo ao considerar as diferenças pessoais (e.g. gênero, etnia, cultura) entre indivíduos enquadrados em uma mesma categoria diagnóstica como um fator a ser levado em conta pelo terapeuta, o documento não aborda a questão da influência da cultura na determinação dos próprios parâmetros epistemológicos e nosológicos que sustentam a investigação científica em psicopatologia e parece desconsiderar ou ignorar o problema. Conforme apontam Wendt e Slife (2007), o relatório parte de uma premissa epistemológica particular sem qualquer justificativa baseada em evidências ou em um argumento lógico, o que violaria o princípio fundamental do documento. Ainda segundo os mesmos autores, ao sequer explicitar a adoção de uma noção empirista de evidência científica, o documento revela que o "empirismo não é visto [no relatório] como uma filosofia ou epistemologia particular, mas como uma janela transparente para o modo como as coisas são" (Wendt \& Slife, 2007, p. 613), o que explicitaria a adoção do representacionismo e do realismo científico (Starcevic, 2003). A crítica expõe um problema central para a discussão aqui proposta, que ocorre quando os pressupostos filosóficos que sustentam uma proposta normativa da investigação científica não são explicitamente considerados: assumir como universal uma perspectiva epistemológica particular, ainda que tacitamente.

É objetivo deste trabalho (1) apresentar uma reflexão crítica sobre os problemas potenciais da utilização dos ECAs na pesquisa clínica em psicologia, bem como o modo de compreender seus resultados, conforme proposto no relatório da APA; e (2) apresentar um caminho para uma possível solução desses problemas no nível epistemológico. Para isso, de acordo com o dito anteriormente, assumiremos três pontos como pressuposto: (1) todo método científico deve estar subordinado à epistemologia; (2) há divergências entre diferentes propostas epistemológicas; e (3) ao estabelecer um método ou desenho específicos como produtor de resultados mais evidentes do que outros, se está assumindo, como premissa, uma perspectiva epistemológica particular.

Para discutir esses pontos, recorremos fundamentalmente ao trabalho de Boaventura de Souza Santos (2009) sobre o "colonialismo epistemológico", a fim de elaborar a crítica à proposição de que o ECA produz as melhores evidências dentre os desenhos e métodos utilizados na pesquisa de eficácia clínica em psicoterapia. Além disso, também serão analisadas algumas objeções às práticas baseadas em evidências e ao ECA encontradas na literatura. E, por fim, algumas ressalvas do próprio grupo da APA sobre o que estão desenvolvendo serão apesentadas. Refletiremos, portanto, sobre a crítica e a metacrítica dos ECAs, buscando esboçar uma síntese a partir do diálogo entre pontos de vista opostos sobre a melhor forma de conceber, utilizar e valorar os ECAs, e como interpretar e considerar seus resultados. Para isso, apresentaremos as divergências entre a proposta metodológica do positivismo e a epistemologia pragmatista, utilizando a filosofia da ciência do comportamento de B. F. Skinner $(1953,1969,1974)$ o behaviorismo radical - como referencial conciliador.

\section{Algumas críticas à Práticas Baseadas em Evidências e aos Ensaios Clínicos Aleatorizados}

Muitas são as críticas ao projeto de MBE como um todo e à utilização dos ECAs em particular (Rees, 2000). Essas críticas se dão em variados níveis: filosófico-epistemológico, lógico, teórico, metodológico, ético e político. O objetivo desta reflexão não é um aprofundamento em cada um desses níveis, mas identificar elementos que nos permitam avaliar de que maneira e até que ponto - o ECA poderia se configurar como estratégia válida de investigação científica no contexto crítico apontado pelas epistemologias pós-modernas, conforme compreendidas por Santos (1989).

Em síntese, Santos (1989) propõe dois limites importantes para a ciência moderna. O primeiro se refere à impossibilidade de se tratar de pressupostos epistemológicos sem levar em conta o contexto social no qual são produzidos e a indissociável posição política nela implícita. O segundo aponta para a necessidade da interpretação dos dados na construção do saber científico. Mesmo que em níveis e de modos diferentes, variando em função das características próprias do fenômeno estudado, em última análise, nenhuma epistemologia daria conta da produção de conhecimento sem alguma interferência hermenêutica.

A primeira crítica apresentada por Rees (2000), de cunho eminentemente político, diz respeito ao impacto ideológico do próprio título dado ao movimento:

Primeiro, o nome. É claro que não é apenas enfadonho, mas também pernicioso. Alguém gostaria de se vangloriar de praticar medicina não baseada em evidências? No entanto, este nome procura uma exclusividade para uma igreja particular de crença, particularmente aquela baseada nos ECAs. Os oponentes são, de alguma forma, ridiculizados, através do sofisma de confundir o conhecimento confiável com o produzido a partir de um ECA. Um dispositivo retórico talvez, mas pernicioso. (p. 727, grifo nosso) 
A imposição de crenças particulares como se fossem evidências universais, conforme destacada por Rees (2000), é apresentada por Santos (2009) como um mecanismo de dominação ideológica que ele chama de "pensamento abissal", característico do "colonialismo epistemológico". Nessa perspectiva, Rees (2000) parece denunciar uma posição política implícita no alicerce epistemológico da MBE. Há uma desqualificação não só de outras práticas, mas, especialmente, das diferentes propostas metodológicas de investigação que, sustentadas em bases epistemológicas diferentes daquela em que os ECAs se edificaram, não compartilham dos critérios propostos para que se estabeleça a hierarquização das evidências disponíveis. Sem nos aprofundarmos nos diferentes significados e preconceitos que o termo "evidência" enseja, essa postura pode ser enquadrada como uma proposta hegemonizadora, uma vez que impõe uma estratégia de investigação supostamente superior às demais.

Provavelmente, o exemplo mais evidente dessa posição seja o positivismo, ao propor uma epistemologia com caráter universal, considerando-se o apogeu da história evolutiva do pensamento humano (Comte, 1848/1998). Assim, a epistemologia positivista estaria acima das ideologias e das forças políticas, constituindo-se em um alicerce seguro para abordagens científicas que visassem o desvelamento do real, isento de vieses. Partindo da separação ontológica entre observador e objeto, e operando através do controle rigoroso da influência da subjetividade do primeiro sobre o segundo, essa perspectiva supera o realismo direto ou ingênuo e entende que os processos lógicos dedutivos e indutivos se constituem como condição necessária para a correta significação dos dados empíricos (i.e. obtidos por observação) na produção do conhecimento. Porém uma análise histórica da ciência sugere que o avanço científico (Kuhn, 1996/1962) especialmente no que se refere a grandes saltos de entendimento - parece se dever essencialmente a uma abordagem inferencial de investigação, baseada na formulação de hipóteses, a qual o filósofo pragmatista Charles Pierce chamou de formas abdutivas de raciocínio (Fann, 1970).

A emergência de novos modelos, capazes de criar espaço para indagações nunca antes pensadas e caminhos de entendimento até então inexistentes, depende da articulação entre diferentes facetas do fenômeno, tal como se apresentam para um grupo específico de pessoas em determinado contexto (i.e. uma comunidade científica). Articulação essa que é forjada na subjetividade de quem a elabora e a partir da qual o raciocínio lógico formal (i.e. dedução e indução) poderá ajudar a validar seu produto. Entretanto o documento parece desconsiderar a influência sociopolítica e socioeconômica na própria identificação das questões que serão eleitas como problemas de pesquisa e das hipóteses concebidas para elas. Essas concepções estão inevitavelmente confinadas às possibilidades de significação ofertadas pelas características próprias do tempo e lugar em que emergem, conforme as regras socioculturais vigentes (Santos, 2009; Wittgenstein, 1953/1980). E, ao se apresentarem como universais, acabam por impor uma agenda científica particular, submetendo outras matrizes de entendimento aos problemas e hipóteses típicos de sua localidade, expressando, assim, seu potencial colonizador (Santos, 2009). Esse potencial se atualiza quando um método específico de investigação de problemas e hipóteses forjados em um contexto cultural particular, mas concebido como universalmente aplicável, é estabelecido como o produtor da melhor evidência.

Ou seja, ainda que a perspectiva representacionista do realismo científico assuma a impossibilidade de uma apreensão perfeita da realidade, um conjunto de normas metodológicas é efetivamente empregado com a finalidade de reduzir ao máximo a influência da subjetividade do observador nos resultados da pesquisa. Conforme afirma Tourinho (1996), ao apresentar a crítica do filósofo neopragmatista Richard Rorty aos contornos mais recentes do representacionismo,

não se trata mais de acreditar que é possível chegar a uma representação exata e isenta da realidade, mas de postular a existência de critérios de valor universal e a-histórico, que devem ser incorporados por toda prática voltada para a construção do conhecimento válido, ou, de outro modo, trata-se de negar o caráter histórico-cultural dos critérios a partir dos quais as reivindicações a conhecimento são contemporaneamente julgadas em uma cultura, e de negar a possibilidade de emergência de novas práticas discursivas. (p. 44)

Para Rorty (1999), mesmo reconhecendo seus limites, ao partir de uma concepção do conhecimento como universal e necessário, o realismo representacionista torna-se dogmático e autoritário. A questão crucial, aqui, parece ser se a epistemologia estaria, enquanto produto humano, inscrito na cultura, submetida a determinações sociológicas e antropológicas; ou se, pelo contrário, as elaborações teóricas das ciências que se ocupam do fenômeno humano se edificariam em pressupostos epistemológicos a priori. Se não temos a resposta para essa questão, podemos observar posições claramente antagônicas a esse respeito. De um lado uma epistemologia positivista, de concepção ontológica realista, considerando a natureza um ente dado que deve ser desvelado ou ter seu funcionamento descoberto pelo uso do método científico, conforme por ela concebido. Do outro lado, as concepções críticas a essa visão (i.e. contextualistas), que não compreendem a subjetividade do observador como uma potencial produtora de vieses, de erros corrigíveis pelo método, mas sim como elemento indissociável do próprio fenômeno estudado (Pepper, 1942/1970). 


\section{As questões ontológica e hermenêutica da interpretação dos resultados dos ECAs}

Neste ponto, parece oportuno explicitar o interesse dos autores na discussão sobre a pertinência do uso de metodologias oriundas de propostas epistemológicas modernas e supostamente positivistas em um contexto crítico, apresentado pelas matrizes pós-modernas (Santos, 1989). Esta reflexão parte de uma inquietação de autores adeptos de métodos nomotéticos de pesquisa e cujo currículo acadêmico inclui a publicação de ECAs (e.g. Sampaio, Jorge, Martins, Gandarela, Hayes-Skelton, Bernik, \& Lotufo-Neto, 2020): se por um lado as críticas ao realismo, representacionismo e positivimo são pertinentes, parece incontestável o maior poder preditivo das teorias psicológicas amparadas pelo método experimental.

Em meio a esse conflito e diante das divergências teóricas que caracterizam a psicologia, um autor improvável, por reconhecidamente controvertido, parece pavimentar o caminho para uma possível conciliação entre o método experimental e as epistemologias pós-modernas. Conforme apontado por estudiosos e comentadores do behaviorismo, a posição epistemológica de B. F. Skinnerproponente de uma filosofia da ciência do comportamento humano a qual chamou de Behaviorismo Radical parece estar erroneamente associada ao positivismo em geral e à sua versão "lógica" do chamado Círculo de Viena, em particular (Matos, 1995; Smith, 1989). Sem ter priorizado o aprofundamento nessa questão, ao assumir a posição ontológica materialista, Skinner o faz por motivos práticos, e não por um alinhamento ao realismo representacionista do positivismo, assumindo uma posição agnóstica em relação à existência do mundo objetivo, dado a priori (Abib, 1999). Como as explicações internalistas fracassaram em todas as ciências, dando lugar à identificação das relações entre variáveis externas ao objeto ou fenômeno, a partir do uso do método científico tal como descrito pelo positivismo, a concepção monista materialista de homem favorecia a eliminação de hipóteses causais que atrapalhavam a investigação dos efeitos das variáveis ambientais no comportamento humano (Skinner, 1953).

Embora essa concepção agnóstica ${ }^{1}$ não se configure como necessariamente pós-moderna, tampouco pode ser enquadrada como positivista (Abib, 1999). As diferenças de pressuposto entre o behaviorismo radical de Skinner e o positivismo, apesar de não os colocarem necessariamente como propostas inconciliáveis (na medida em que, entre outras coisas, Skinner não nega o mundo real e adota o método experimental), também não permitem afirmar que elas sejam plenamente compatíveis.

O principal elemento de compatibilidade entre essas filosofias da ciência é, provavelmente, a adoção

1 Embora muitos autores interpretem a posição de Skinner como ontologicamente agnóstica, existem outros que não concordam com essa conclusão. Uma interessante discussão sobre a ontologia do comportamento em Skinner pode ser encontrada em Zilio (2012). da previsão e do controle de fenômenos naturais como elemento fiador da veracidade do conhecimento, o que afasta ambos de uma perspectiva hermenêutica pura. Entretanto, embora o contextualismo das epistemologias pós-modernas (Santos, 1989) negue a possibilidade de uma representação da "Verdade" sobre os fenômenos naturais, a perspectiva pragmática acaba por adotar, em grande medida, métodos desenvolvidos com ambições representacionistas. Para Rorty (1998), "a predição é uma condição necessária para colocarmos algo em uma caixa com o rótulo de "ciência"' (p. 20). Portanto, quando Skinner (1953) afirma que a única evidência de que o conhecimento científico é verdadeiro é sua capacidade de prever e controlar fenômenos naturais, ele não está necessariamente propondo que a ciência revele uma verdade sobre o mundo real. É como se ele operasse sempre no nível do fenômeno, concebido pragmaticamente como matéria, sem especular a existência ou não da realidade em si.

Apesar de não ser um tema central de sua obra, Skinner $(1953,1969,1974)$ critica a noção de conhecimento como representação da realidade ao defender que a principal função das ciências não seria revelar os reais determinantes dos fenômenos naturais (incluindo o comportamento humano), mas produzir soluções para os problemas práticos da sociedade. A decorrência principal disso, para a questão aqui posta, é que a validade de uma teoria residiria menos na correspondência com o real do que na efetividade de suas tentativas de solucionar problemas, tal como se apresentam e são concebidos, por uma comunidade específica em determinado contexto. E, para Skinner, os métodos oriundos da perspectiva positivista seriam, até aquele momento, os que proporcionavam maior capacidade de predição e, consequentemente, de intervir e solucionar problemas práticos (Sampaio, 2005).

Esse posicionamento afasta Skinner de pressupostos típicos da modernidade e o aproxima da perspectiva epistemológica do pragmatismo, especialmente no que se refere ao critério de verdade. Para o pragmatismo, a teoria verdadeira é aquela cuja explicação funcionou melhor até o momento, para os objetivos de quem empreende a investigação (James, 1907/1948). Assim, os objetivos da pesquisa científica estariam sempre norteados por seus efeitos práticos e pelos interesses do cientista.

Numa perspectiva pragmática, a previsão e o controle sobre fenômenos naturais pode ser um objetivo estabelecido pelo interesse em resolver problemas considerados relevantes, sem necessariamente revelar nada sobre uma realidade para além do fenômeno, podendo qualquer explicação científica deixar de ser verdadeira se outra vier a funcionar melhor para os mesmos fins (Dewey, 1938/1960). E ainda que os métodos ajudem na avaliação da qualidade da explicação produzida, tanto o enquadramento de determinado fenômeno como problema, como a identificação de sua relevância, dependerão de um critério valorativo anterior, forjado pela cultura e estabelecido fora do escopo da investigação 
científica. Além disso, numa perspectiva ontológica contextualista (Pepper, 1942 /1970), o objeto de estudo de uma ciência não é um ente real em si, independente do sujeito, sendo, em vez disso, determinado pela relação que o sujeito estabelece com o fenômeno estudado, tal como a ele se apresenta (Rorty, 1998; Witgeinstein, 1953/1988). Em outras palavras, a delimitação fenomenológica de um objeto de estudo não é dada a priori, mas é estabelecida sempre com alguma arbitrariedade. E, diferente da proposta positivista, que pretende definir os objetos de estudo a partir de uma aproximação descritiva de sua real natureza e forma, o pragmatismo propõe que esse recorte se dê (e, necessariamente, se dá) pelas vantagens que proporciona para os objetivos de quem o define (Dewey, 1938/1960; James, 1907/1948). Nas palavras de Skinner (1974), “uma proposição é 'verdadeira' na medida em que ajuda o ouvinte a agir efetivamente na situação por ela descrita" (p. 235).

Ao assumir tal agnosticismo ontológico, a ciência experimental sai do lugar de reveladora da verdade para se estabelecer como instrumento útil na previsão e controle de fenômenos naturais. Desse modo, seria perfeitamente legítima a investigação científica a partir da proposta ontológica realista, desde que reconhecida a arbitrariedade presente na separação entre sujeito e objeto, justificando-a por suas eventuais vantagens práticas sobre outros pressupostos.

O mesmo tipo de raciocínio pode ser aplicado em relação à psicopatologia, quando se supõe a existência de uma estrutura latente aos transtornos mentais (VanDorn et al., 2016) e que esta se adequa às descrições nosológicas vigentes (Casey, Craddock, Cuthbert, Hyman, \& Ressler, 2013). Com efeito, muitas são as propostas clínicas em psicologia que não adotam a nosologia psiquiátrica como referência diagnóstica. Mesmo entre as terapias cognitivocomportamentais, que tradicionalmente se apoiam nessas classificações, existe um movimento propondo perspectiva alternativa, em que os transtornos mentais são compreendidos como redes complexas de relações entre processos psicológicos que estariam configuradas de modo a produzir sofrimento (Hofmann, Curtiss, \& McNally, 2016). De forma similar ao que ocorre com o materialismo skinneriano, a terapia cognitivo-comportamental baseada em processo parece assumir uma postura agnóstica em relação à existência de uma estrutura latente aos transtornos mentais, focando a investigação clínica e a intervenção nas relações funcionais entre operações e processos presentes na interação da pessoa com seu contexto ambiental (Hofmann \& Hayes, 2018).

Como fica claro nesse exemplo, o levantamento de novas hipóteses e propostas de investigação científica em psicopatologia estará necessariamente comprometida com algum pressuposto ontológico e epistemológico, ainda que estes não tenham sido explicitados ou verificados. Enquanto pensamento abdutivo, todas essas diferentes inferências sobre a natureza da psicopatologia podem (e devem) ser adotadas caso funcionem melhor que outras explicações na produção de conhecimento e na promoção de saúde e bem-estar (noções estas também comprometidas com os mesmos pressupostos). A classificação nosológica, portanto, assim como qualquer delimitação fenomenológica de um objeto, não deve ser proposta como a representação de uma realidade independente, mas como uma produção teórica que se legitima, em última análise, por suas vantagens práticas para determinados objetivos, em determinados contextos; e não por capturar o substrato ou a essência do quadro clínico descrito.

\section{Considerações finais}

É na perspectiva pragmática que os ensaios clínicos randomizados podem ser compreendidos como uma ferramenta útil para verificar a eficácia de algumas terapias, em determinadas populações clínicas, definidas a partir de uma perspectiva nosológica particular. Assim como ocorre com o método experimental na ciência do comportamento de Skinner, os ECAs não precisam ter seus resultados interpretados a partir de uma epistemologia representacionista, como a revelação de uma verdade una, objetiva. Seu valor, portanto, reside no fato de ser mais uma forma de abordar o fenômeno clínico, apropriado para responder a determinadas perguntas, assim como outros desenhos e propostas metodológicas podem ser mais adequados às perguntas que visam responder. Seu valor está em produzir dados que atestem a eficácia de propostas terapêuticas cujas características se adequam ao método de investigação.

Dessa forma, no contexto crítico apresentado por Santos $(1999,2009)$, não haveria um problema intrínseco na proposta metodológica dos ECAs, desde que não seja adotada de forma hegemônica e que seus resultados não sejam interpretados como a revelação da verdade. Nesse sentido, os ECAs seriam mais uma possibilidade de desenho experimental que pode ter seus resultados interpretados a partir de diferentes matrizes de entendimento, sendo a perspectiva positivista uma delas, mas não a única.

Ainda que a força tarefa da APA conte com autores de perspectivas teóricas diversas, a hipervalorização dos ECAs como produtores de evidências gera uma confiança excessiva em abordagens psicoterápicas que, por apresentar afinidades com o desenho experimental do ECA, são mais estudadas e acabam se estabelecendo como práticas baseadas em evidências (e.g., terapias cognitivo-comportamentais). Já outras terapias passam a ser vítimas do inverso, quando essas abordagens menos afinadas aos ECA acabam sendo desprestigiadas por não haver evidência suficiente a seu favor. É importante lembrar - e isso é apontado pela força-tarefa da APA (American Psychological Association, 2006), que a ausência de evidência não é uma evidência de ausência (Hollom, 2015). E que, para além da ausência de testes considerados adequados 
(i.e. ECAs), outros fatores conduzem à discrepante produção de evidências entre diferentes abordagens e modelos psicoterápicos.

Diferente do que ocorre com a farmacoterapia, em que a administração do princípio ativo pode ser controlada precisamente em pílulas e comprimidos, intervenções psicoterapêuticas, por sua natureza dialógica, não se adaptam facilmente a tal padronização, o que as torna pouco afeitas às exigências metodológicas do ECA (Haaga \& Stiles, 2000; Starcevic, 2003). Não surpreende, portanto, que as terapias que acumulam maior evidência de eficácia são diretivas, estruturadas e direcionadas a transtornos específicos. O que não podemos afirmar é que por esse motivo elas são mais eficazes do que outras terapias que, por suas características mais idiográficas, não se adequam a métodos nomotéticos de investigação (Barlow \& Nock, 2009; Piccirillo \& Rodebaugh, 2019).
Diante da proliferação de novas propostas psicoterapêuticas, das mais diversas bases teóricas, para diferentes quadros clínicos, surge uma demanda legítima pela aferição científica da qualidade dessas terapias. O movimento das Práticas Baseadas em Evidências em Psicologia tem um importante papel nesse processo, mas não deve omitir as bases epistemológicas que sustentam suas propostas, cuidando para não ensejar a rejeição de terapias cujas bases teóricas não compartilhem os mesmos pressupostos, considerando o status pré-paradigmático da psicologia clínica e estando sempre aberta ao diálogo crítico e criterioso com propostas metodológicas alinhadas a matrizes epistemológicas variadas.

\section{Agradecimento}

Agradecemos ao Gustavo Camps Pimenta pela leitura crítica do manuscrito e por suas valiosas sugestões.

\title{
The place of Randomized Clinical Trials in psychotherapy research: an epistemological critique
}

\begin{abstract}
The randomized controlled clinical trial (RCT) is considered the type of methodological design with the greatest power to verify the efficacy of psychotherapies. However, especially from the second half of the twentieth century, many criticisms directed at the epistemological conceptions underlying the so-called "hard sciences" have also affected the studies that adopted this design. This article is a critical reflection on some of the objections made to randomized clinical trials, evaluating how and to what extent these trials could be configured as a valid scientific research strategy in this critical context. We concluded that the RCT should be used - as long as it is performed in a critical context - due to its pragmatic value, as a producer of predictions and interventions capable of solving clinical problems, inevitably defined and established from the particular point of view of a community.
\end{abstract}

Keywords: randomized controlled trial, evidence-based practice, knowledge, pragmatism, behaviorism.

\section{La place des essais cliniques randomisé dans la recherche en psychothérapie : une critique épistémologique}

Résumé: L'essai clinique randomisé est considéré comme le type de conception méthodologique ayant le plus puissant pour vérifier l'efficacité des psychothérapies. Cependant, surtout depuis la seconde moitié du XXe siècle, de nombreuses critiques adressées aux conceptions épistémologiques qui sous-tendent les sciences dites « dures » ont également affecté, dans le cadre des sciences de la santé, les études qui ont adopté cette conception. Cet article est une réflexion critique sur certaines des objections faites aux essais cliniques randomisés, évaluant comment et dans quelle mesure ceux-ci pourraient être configurés comme une stratégie valide de recherche scientifique dans le contexte critique signalé. On en conclu que l'ECA peut et doit être utilisé - à condition que ce soit dans un contexte critique - pour sa valeur pragmatique, en tant que producteur de prédictions et d'interventions capables de résoudre des problèmes cliniques, inévitablement définies et établies du point de vue particulier d'une communauté.

Mots-clés : essai clinique randomisé, pratiques factuelles, épistémologie, pragmatisme, behaviorisme.

\section{El lugar de los Ensayos Clínicos Aleatorizados en la investigación en psicoterapia: una crítica epistemológica}

Resumen: El ensayo clínico aleatorizado (ECA) se considera el tipo de diseño metodológico con mayor poder para verificar la eficacia de las psicoterapias. Sin embargo, especialmente desde la segunda mitad del siglo XX, muchas críticas dirigidas a las concepciones epistemológicas subyacentes a las llamadas "ciencias duras" también han afectado, dentro del alcance de las ciencias de la salud, los estudios que adoptan este diseño. Este artículo es una reflexión crítica sobre algunas de las objeciones hechas a los ECA, evaluando cómo y en qué medida podrían configurarse como una estrategia de investigación científica válida en este contexto crítico. Se concluye que el ECA puede y debe usarse, siempre y cuando se encuentre en un contexto 
crítico, por su valor pragmático como productor de predicciones e intervenciones capaces de resolver los problemas clínicos inevitablemente definidos y establecidos desde el punto de vista particular de una comunidade.

Palabras clave: ensayo clínico aleatorizado, prácticas basadas en evidencia, epistemología, pragmatismo, behaviorismo.

\section{Referências}

Abib, J. A. D. (1999). Behaviorismo Radical e discurso pós-moderno. Psicologia: Teoria e Pesquisa, 15(3), 237-247. Recuperado de http://www.scielo.br/pdf/ptp/ v15n3/07.pdf

American Psychological Association. (2006). Presidential Task Force on Evidence-based Practice. Evidence-based practice in psychology. American Psychologist, 61(4), 271-285. doi: 10.1037/0003-066X.61.4.271

Barlow, D. H. \& Nock, M. K. (2009). Why can't we be more idiographic in our research? Perspectives on Psychological Science, 4(1), 19-21. doi: 10.1111/j.17456924.2009.01088.x

Beck, A. T. (1964). Thinking and depression: II. Theory and therapy. Archives of General Psychiatry, 10(6), 561-571. doi: 10.1001/archpsyc.1964.01720240015003

Butler, A. C., Chapman, J. E., Forman, E. M., \& Beck, A. T. (2006). The empirical status of cognitive-behavioral therapy: A review of meta-analyses. Clinical Psychology Review, 26(1), 17-31. doi: 10.1016/j.cpr.2005.07.003

Casey, B. J., Craddock, N., Cuthbert, B. N., Hyman, S. E., Lee, F. S., \& Ressler, K. J. (2013). DSM-5 and RDoC: Progress in psychiatry research? Nature Reviews Neuroscience, 14(11), 810-814. doi: 10.1038/nrn3621

Comte, A. (1998). Discours sur l'ensemble du positivisme. Paris: GF Flammarion. (Obra original publicada em 1848)

Cook, S. C., Schwartz, A. C., \& Kaslow, N. J. (2017). Evidence-based psychotherapy: Advantages and challenges. Neurotherapeutics, 14(3), 537-545. doi: 10.1007/s13311-017-0549-4

Descartes, R. (2007). Regras para a orientação do espírito. São Paulo, SP: Martins Fontes. (Obra original publicada em 1684)

Dewey, J. (1960). Logic: The theory of inquiry. New York: Rinehart and Winston. (Obra original publicada em 1938)

Fann, K. T. (1970). Peirce's theory of abduction. Den Haag: Martinus Nijhoff.

Haaga, D. A. F., \& Stiles, W. B. (2000). Randomized clinical trials in psychotherapy research: Methodology, design, and evaluation. In C. R. Snyder \& R. E. Ingram (Eds.), Handbook of psychological change: Psychotherapy processes \& practices for the 21st century (pp. 14-39). Hoboken: John Wiley \& Sons.

Hayes, S. C., \& Hofmann, S. G. (Eds.). (2018). Process-based CBT: The science and core clinical competencies of cognitive behavioral therapy. Oakland: New Harbinger.
Hofmann, S. G., \& Hayes, S. C. (2018). The future of intervention science: Process-based therapy. Clinical Psychological Science, 7(1), 37-50. doi: 10.1177/2167702618772296

Hofmann, S. G., Curtiss, J., \& McNally, R. J. (2016). A Complex network perspective on clinical science. Perspectives on Psychological Science: A Journal of the Association for Psychological Science, 11(5), 597-605. doi: 10.1177/1745691616639283

Hollom, S. D. (2006). Randomized clinical traials. In J. Norcross, R. Levant, \& L. Beutler (Orgs.). Evidence-based practices in mental health: Debate and dialogue on the fundamental questions. Washington, DC: American Psychological Association Press.

Hujoel, P. (2009). Grading the evidence: The core of EBD. Journal of Evidence Based Dental Practice, 9(3), 122-124. doi: 10.1016/j.jebdp.2009.06.007

Ioannidis, J. P. A. (2015). Research and theories on the etiology of mental diseases: Doomed to failure? Psychological Inquiry, 26(3), 239-243. doi: 10.1080/1047840X.2015.1021188

James, W. (1948). Essays in pragmatism. New York: Hafner. (Obra original publicada em 1907)

Kant, E. (1983). Crítica da razão pura. Coleção Os Pensadores (2a ed.). São Paulo, SP: Abril Cultural. (Obra original publicada em 1781)

Kendall, J. M. (2003). Designing a research project: Randomised controlled trials and their principles. Emergency Medicine Journal: EMJ, 20(2), 164-168. doi: $10.1136 /$ emj.20.2.164

Klein, D. F. (1997). Control groups in pharmacotherapy and psychotherapy evaluations. Treatment, l(1), Article 1a. doi: 10.1037/1522-3736.1.1.11a

Kuhn, T. S. (1996). The structure of scientific revolutions (3rd ed.). Chicago, IL: University of Chicago Press. (Trabalho original publicado em 1962)

Lambert, M., \& Ogles, B. (2004). The efficacy and effectiveness of psychotherapy. In M. J. Lambert (Ed.), Bergin and Garfield's handbook of psychotherapy and behavior change (5th ed., pp. 139-193). New York: Wiley.

Matos, M. A. (1995). Behaviorismo metodológico e behaviorismo radical. In B. Rangé (Org.), Psicoterapia comportamental e cognitiva: Pesquisa, prática, aplicações e problemas (pp. 13-19). Campinas, SP: Editorial Psy.

Pepper, S. C. (1970). World hypotheses: A study in evidence. Berkeley, CA: University of California Press. (Trabalho original publicado em 1942) 
Piccirillo, M. L., \& Rodebaugh, T. L. (2019). Foundations of idiographic methods in psychology and applications for psychotherapy. Clinical Psychology Review, 71, 90-100. doi: 10.1016/j.cpr.2019.01.002

Rees, J. (2000). Evidence-based medicine: The epistemology that isn't. Journal of the American Academy of Dermatology, 43(4), 727-729. doi: 0.1067/ mjd.2000.108368

Rorty, R. (1979). Philosophy and the mirror of nature. Princeton, NJ: Princeton University Press.

Rorty, R. (1998). Pragmatismo, filosofia analítica e ciência. In P. R. M. Pinto, C. Magro, \& L. Guimarães (Orgs.), Filosofia analítica, pragmatismo e ciência (pp. 15-29). Belo Horizonte, MG: Humanitas.

Rorty, R. (1999). Pragmatism as anti-authoritarianism. Revue Internationale De Philosophie, 53(207[1]), 7-20.

Sampaio, A. A. S. (2005). Skinner: sobre ciência e comportamento humano. Psicologia: Ciência e Profissão, 25(3), 370-383. doi: 10.1590/S1414-98932005000300004

Sampaio, T. P. A., Jorge, R. C., Martins, D. S., Gandarela, L. M., Hayes-Skelton, S., Bernik, M. A., \& Lotufo-Neto, F. (2020). Efficacy of an acceptance-based group behavioral therapy for generalized anxiety disorder. Depression and Anxiety, 37(9), 1-15. doi: 10.1002/da.23021

Santos, B. S. (1989). Introdução a uma ciência pós-moderna. Rio de Janeiro, RJ: Edições Graal.

Santos, B. S. (2009). Para além do pensamento abissal: Das linhas globais a uma ecologia de saberes. In B. S. Santos \& M. P. Meneses (Orgs.), Epistemologias do sul (pp. 3356). Coimbra: Edições Almedina.

Shorter, E. (2015). The history of nosology and the rise of the Diagnostic and Statistical Manual of Mental Disorders. Dialogues in Clinical Neuroscience, 17(1), 59-67.

Skinner, B. F. (1953). Science and human behavior. New York: The Macmillan Company.

Skinner, B. F. (1969). Contingencies of reinforcement: A theoretical analysis. New York: Appleton-Century-Crofts.
Skinner, B. F. (1974). About behaviorism. London: Jonathan Cape.

Smith. L. D. (1989). Behaviorism and logical positivism. Stanford: Stanford University Press.

Solomon, M. (2011). Just a paradigm: evidence-based medicine in epistemological context. European Journal for Philosophy of Science, 1, 451-466. doi: 10.1007/ s13194-011-0034-6

Starcevic, V. (2003). Psychotherapy in the era of evidence-based medicine. Australasian Psychiatry, 11(3), 278-281. doi: 10.1046/j.1440-1665.2003.00575.x

Tourinho, E. Z. (1996). Behaviorismo, representacionismo e pragmatismo. Temas em Psicologia, 4(2), 41-56.

VanDorn, R. A., Desmarais, S. L., Grimm, K. J., Tueller, S. J., Jhonson, K. L., Sellers, B. G., \& Swartz; M. S. (2016). The latent structure of psychiatric symptoms across mental disorders as measured with the PANSS and BPRS-18. Psychiatry Research, 30(245), 83-90. doi: 10.1016/j.psychres.2016.08.029

Wendt, D. C., Jr., \& Slife, B. D. (2007). Is evidence-based practice diverse enough? Philosophy of science considerations. American Psychologist, 62(6), 613-614. doi: 10.1037/0003-066X62.6.613

Wittgenstein, L. (1980). Investigações filosóficas. São Paulo, SP: Nova Cultural. (Obra original publicada em 1953)

Wolpe, J. (1968). Psychotherapy by reciprocal inhibition. Conditional Reflex, 3, 234-240 doi: 10.1007/ BF03000093

Zilio, D. (2012). Relacionismo substancial: A ontologia do comportamento à luz do behaviorismo radical. Psicologia: Teoria e Pesquisa, 28(1), 109-118. doi: 10.1590/S0102-37722012000100014

Recebido: 01/05/2020

Revisado: $20 / 09 / 2020$

Aprovado: 01/12/2020 